ISSN: 2602-8085

www.cienciadigital.org

Vol. 3, N³.3, p. 309 - 318, septiembre, 2019

\title{
Infección broncopulmonar por lophomona blattarum en paciente inmunocompetente: primer reporte en Ecuador
}

\section{Lophomona blattarum bronchopulmonary infection in an immunocompetent patient: first report in Ecuador}

Nataly Sofía Valdiviezo Allauca. ${ }^{1}$, Mayra Silvana Chávez Berrones. ${ }^{2}$, Cynthia Desire Merino Guerrero. ${ }^{3}$ \& Jessica Belén Ayala Vaca. ${ }^{4}$

Recibido: 17-06-2019/Revisado: 25-07-209 /Aceptado: 15-08-2019/ Publicado: 06-09-2019

\begin{abstract}
DOI: https://doi.org/10.33262/cienciadigital.v3i3.3.823
The multiflagellated protozoan named Lophomona blattarum (LB) is a potential cause of clinically significant bronchopulmonary infection, although it is a rare infection of the respiratory tract with a nonspecific clinic, and with a diagnosis of difficult determination based on the visualization of the parasite under microscopy, they have presented a considerable number of cases around the planet. This article reports the case of a young adult without compromise of his immunity, who has variable respiratory symptoms, in addition to right pleural effusion and cavitation in the right upper lobe, who after diagnosis is diagnosed by infection by Lophomona spp. Through visualization of said parasite in bronchoalveolar lavage, starting treatment with metronidazole with clinical and radiological improvement.
\end{abstract}

Keywords: Lophomona, pleural effusion, cavitation.

\section{RESUMEN}

El protozoo multiflagelado de nombre Lophomona blattarum (LB) es un potencial causante de infección broncopulmonar clínicamente significativa, pese a que es una

\footnotetext{
${ }^{1}$ Médico residente de Neumología de Hospital de Especialidades de las Fuerzas Armadas No1, n.atthy89@hotmail.com

${ }^{2}$ Médico residente de Neumología de Hospital de Especialidades de las Fuerzas Armadas No 1, mayra_mschb@live.com

${ }^{3}$ Médico residente de Unidad de Cuidados Intensivos de Hospital de Especialidades de las Fuerzas Armadas

No 1, cynthiamerinog@gmail.com

${ }^{4}$ Médico residente de Neumología de Hospital de Especialidades de las Fuerzas Armadas No 1, belenayala@outlook.com
} 
infección rara del tracto respiratorio con clínica inespecífica, y con diagnóstico de difícil determinación basado en la visualización del parasito bajo microscopia, se han presentado un número considerable de casos alrededor del planeta. En el presente artículo se reporta el caso de un adulto joven sin compromiso de su inmunidad, que acude con sintomatología respiratoria variable, además de derrame pleural derecho y cavitación en el lóbulo superior derecho, que posterior a la realización de exámenes es diagnosticado de infección por Lophomona spp. Mediante visualización de dicho parasito en el lavado broncoalveolar, iniciándose tratamiento con metronidazol con mejoría clínica y radiológica.

Palabras clave: Lophomona, derrame pleural, cavitación.

\section{INTRODUCCION}

Las afecciones broncopulmonares clínicamente significativas debido a infecciones por protozoos han aumentado paulatinamente en los últimos años, esto debido a un incremento en cuanto a la población que es portadora de algún tipo de inmunodeficiencia, ya sea secundario a infección por el virus de inmunodeficiencia humana (VIH), a terapia inmunosupresora, cáncer o pacientes con alguna enfermedad pulmonar crónica de base, aunque también se puede presentar en menor proporción en personas inmunocompetentes ${ }^{(1)}$. Una proporción de estas infecciones se encuentran ocasionadas por parásitos flagelados, centrando este artículo en uno de ellos, la LB.

La LB es un parasito multiflagelado endocomensal con dos subespecies, lophomona blattarum y lophomona striata, que se encuentran en el intestino posterior de varias especies de cucaracha, ayudando en la degradación de la lingocelulosa y siendo eliminada en heces de dicho vector; una vez desechada por las heces se conforman a manera de quistes que permanecen en el ambiente, para posteriormente ser inhaladas por el ser humano; pese a que la infección hacia los humanos es rara se han presentado alrededor de un centenar de casos alrededor del mundo.

A lo largo de la literatura médica se han reportado 138 casos de infección pulmonar por LB siendo descrito el primer caso por Chen y Mengsin en 1993, la gran mayoría reportados en el continente asiático, específicamente en china. Se han reportado además 6 casos en Perú y 2 en España, y casos aislados en diferentes países alrededor del mundo. Se han descrito algunos factores asociados al desarrollo de infección broncopulmonar por LB como la inmunosupresión teniendo como periodo de tiempo los últimos 5 años previos a la infección por el parasito, con un $69.1 \%$ de los casos reportados, de los cuales $30.9 \%$ presentaban como causa un trasplante previo; además de enfermedades pulmonares obstructivas crónicas como asma y EPOC. Teniendo cierta predilección por el sexo masculino, sin respetar un grupo etario especifico. 
La presentación clínica de la infección broncopulmonar por LB es indistinguible de cualquier proceso que afecte a la vía respiratoria pues los signos y síntomas asemejan a síntomas comunes tales como fiebre, tos, disnea, entre otros, presentándose en un 35\% de los pacientes eosinofilia, sin un rasgo característico en pruebas de imagen, variando entre nodulaciones pulmonares que se han reportado migratorias en casos aislados, cavitaciones, derrame pleural y abscesos. ${ }^{(2)}$

El diagnostico se realiza mediante la observación bajo microscopia del parasito, ya sea en muestras de esputo, lavado broncoalveolar, cepillado bronquial, con un riesgo significativo de falsos positivos debido a la similitud que este parasito presenta con la célula ciliar bronquial, ${ }^{(3,4,5)}$

Se presenta como caso un paciente adulto joven sin inmunodeficiencia conocida, y clínica respiratoria inespecífica, que acude por dolor torácico y tos, con diagnostico por observación de lophomona blatarrum en lavado broncoalveolar, siendo el primer caso reportado de infección broncopumonar por lophomona en el Ecuador.

\section{PRESENTACIÓN DE CASO}

Se trata de un paciente masculino de 24 años de edad, residente en Machala, Ecuador, de profesión militar con actividades de patrullaje, sin antecedentes patológicos personales, familiares ni quirúrgicos. Quien un mes antes de su valoración por Neumología inicia con dolor en hemitórax posterior derecho tipo punzada de moderada intensidad, sin irradiación, acompañado de disnea de grandes a medianos esfuerzos, además de tos con expectoración blanquecina con tinte hemoptoico que se intensifica por las noches durante los tres primeros días y alza térmica no cuantificada durante dos días. Con esta sintomatología el paciente solicita valoración por facultativo quien prescribe paracetamol. Tras tres días de tratamiento y al no presentar mejoría el paciente acude a Hospital de mayor complejidad donde realizan Tomografía simple de tórax observándose derrame pleural, se intenta realización de toracocentesis la cual no es exitosa por lo que se deriva al servicio de Neumología de nuestro Hospital.

A su llegada a nuestro servicio se realiza radiografía de tórax (foto 1)

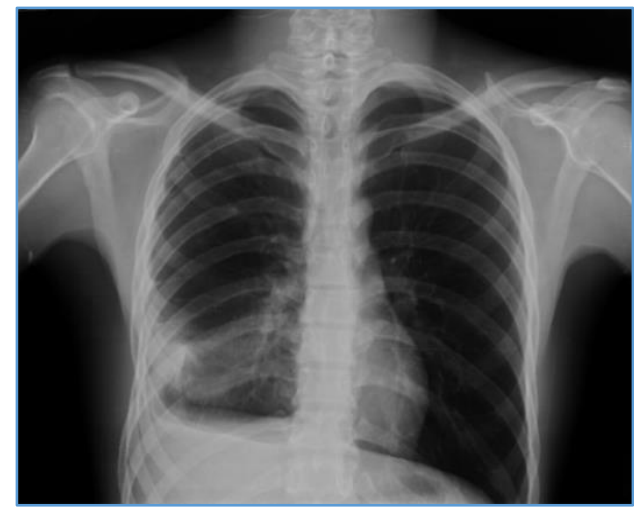

Figura 1. RX de tórax de ingreso, opacidad en campo 
Tomografía de Tórax simple (foto 2 y 3)

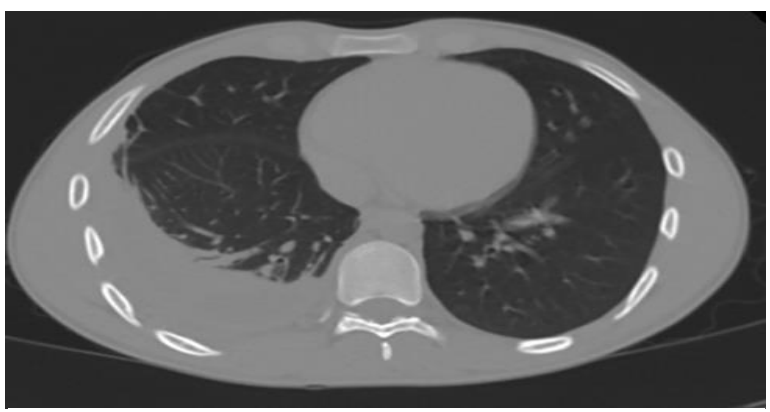

Figura 2. TAC simple de tórax, derrame pleural derecho.

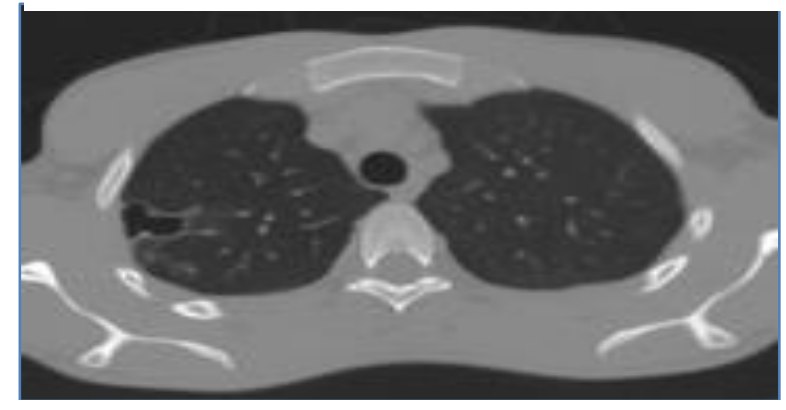

Figura 3. TAC simple de tórax, cavitación apical de campo pulmonar derecho.

Objetivándose derrame pleural derecho y cavitación apical derecha. Debido a la clínica del paciente acompañado de los hallazgos radiológicos y considerando que el paciente no expectoraba, se decidió la realización de una broncoscopia diagnostica para toma de muestras para descartar como tuberculosis pulmonar, y entre otras causas infección por paragonimus westermani.

Durante su hospitalización se realizó exámenes Biometría Hemática con Leucocitos de 6000, Neutrófilos 52.2\% HB: 13g/dl HCTO: 40\%, Glucosa: $74 \mathrm{mg} / \mathrm{dl}$ Creatinina $0.90 \mathrm{mg} / \mathrm{dl}$, Urea: 25mg/dl, PCR: $3.1 \mathrm{mg} / \mathrm{dl}$ PCT: 0.05ng/dl VIH y VDRL negativo, ZIEHL en Esputo y Orina negativo y con quantiferòn para tuberculosis negativo. Eco Torácico demostró derrame tabicado derecho de contenido fibroso en un volumen no mayor de 51 centímetros cúbicos (cc). Además, se planifico Broncoscopia la cual concluyo proceso inflamatorio bronquial leve, se realizó lavado bronquioalveolar y cepillado bronquial a nivel de lóbulo superior derecho, lóbulo medio, y lóbulo inferior derecho se enviaron muestras para estudio citobacteriologico.

El ZIEHL en el cepillado y lavado bronquial fue negativo. Se obtuvo el resultado de la observación de parásitos en fresco del lavado bronquial donde se visualizó Lophomona spp. Se realizó la observación microscópica directa de estructuras con movimiento ondulado 
protozoarias ciliadas sin barrera terminal. De esta manera se confirmó el diagnóstico de infección broncopulmonar por Lophomona spp. (Figura 4)

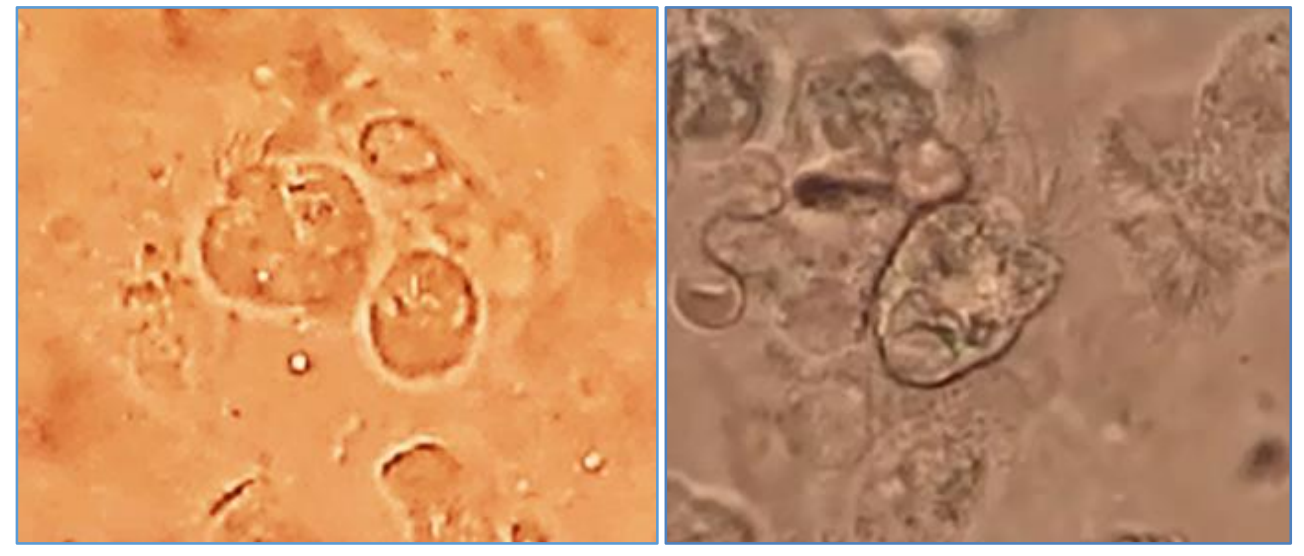

Figura 4.- Lophomona spp en estudio de lavado broncoalveolar

Se inició tratamiento con Metronidazol 500mg vía oral cada 8 horas, cumpliendo 8 días de tratamiento hospitalizado y completando esquema ambulatorio un total de 21 días.

Posterior a de 7 días de iniciado el tratamiento se realizó nueva ecografía torácica en la que observo disminución del derrame derecho septado en 28 centímetros cúbicos (cc). El paciente evoluciona favorablemente desde el punto de vista clínico y radiológico (figura 5).

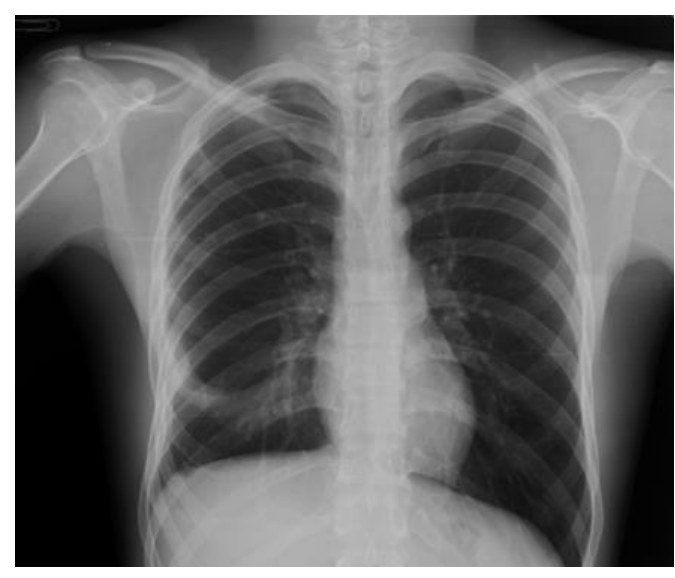

Figura 5.- Radiografía de tórax de control posterior al tratamiento

\section{DISCUSIÓN}

La LB es un parásito presente a nivel del intestino posterior de varias subespecies de cucarachas, siendo endocomensales junto con otros parásitos tales como Nyctotherus sp, Gregarina sp, Amoeba sp, En proporciones de $91.8 \%, 64.5 \%$ y $25.4 \%$ respectivamente siendo 
la LB el parásito menos frecuentemente encontrado con un $13.6 \%$ en un estudio europeo de 110 cucarachas estudiadas ${ }^{(6)}$. Característicamente presentando 50 o más flagelos apicales, con cuerpo de forma piriforme, citoplasma granular con partículas fagocitarias, un diámetro entre 20 -60 um de largo y 12-20 um de ancho, es un parasito que se identifica bajo microscopia óptica.

Tanto la clínica como las descripciones imagenológicas de la infección broncopulmonar por LB son inespecíficas en la mayoría de las publicaciones reportadas. Pese a que la mayoría de casos reportados se presentan en pacientes inmunocomprometidos, existe un número apreciable de casos en paciente inmunocompetentes, teniendo como principal región a nivel mundial de casos reportados de esta patología el continente asiático. Al ser un patógeno inusual se ha reportado no solo a nivel de tracto respiratorio bajo, pues se han reportado 5 casos en la literatura médica de sinusitis con aislamiento de LB en secreciones ${ }^{(7)}$, adicionalmente se encontró en la India también como una coinfección con Mycobacterium tuberculosis en un caso determinado por PCR MTB / RIF (-) en esputo que se manejó con un fármaco antifímico durante 9 meses y se administró metronidazol por vía oral. Hasta su erradicación confirmada por lavado broncoalveolar ${ }^{(12) .}$

En el presente caso no se reporta contacto con animales o vectores, aunque al ser militar tiene la predisposición de encontrarse en regiones selváticas y en condiciones de hacinamiento además de regiones húmedas y pantanosas, lo que se puede presuponer como factor que contribuye a tener contacto con vectores o animales que influyan en la transmisión de dicho parasito.

Los reportes sobre el tema en su gran mayoría provienen de China, probablemente por su densidad poblacional y al consumo cultural de vectores tales como la cucaracha que contribuye a la infección por LB, teniendo en consideración los casos reportados hasta ahora se puede tomar como sugerencia que cualquier paciente con un compromiso de su inmunidad o enfermedad pulmonar crónica que no haya respondido al tratamiento antibiótico convencional debe ser candidato para realización de lavado broncoalveolar en un intento por determinar la presencia de LB. ${ }^{(15)}$ El caso presentado en el presente artículo es llamativo pues se trata de un paciente inmunocompetente sin patología pulmonar crónica previa, en quien se decide inicialmente realizar broncoscopia buscando descartar tuberculosis pulmonar o infección por paragonimus, sin embargo, el diagnóstico fue de Lophomona spp. lo cual hace necesario el aumentar la sospecha de este patógeno incluso en pacientes inmunocompetentes.

En cuanto al diagnóstico la identificación del parasito se basa en su visualización directa. Se ha recomendado distintas coloraciones, tales como hematoxilina/eosina, Giemsa y frotis cervical (Papanicolaou) así como tinción de tricromica de Wheatley. Lo fundamental debe ser considerar la capacidad resolutiva, y recursos de cada institución ${ }^{(16)}$. 
ISSN: 2602-8085

Se describe que no se puede considerar como parámetro la mejoría clínica posterior al tratamiento con metronidazol como determinante de que la infección fue efectivamente por LM ya que el metronidazol cubre además bacterias anaerobias pudiendo encubrirse una infección atípica pulmonar ${ }^{(16)}$. Sin embargo y como se puede observar en nuestro paciente la respuesta de la infección al tratamiento con metronidazol es óptima.

El tratamiento al momento se encuentra descrito a base de metronidazol, pues no se ha demostrado que exista resistencia por parte del parasito a esta medicación, con un tiempo estimado de tratamiento de 3 semanas, recomendándose 500mg vía oral cada 8 horas por 21 días, dosis que fue prescrita en nuestro paciente, como tratamientos alternativos se recomienda Albendazol 400mg vía oral cada día por 5 días, o Tinidazol 500mg vía oral cada 12 horas por 5 días.

\section{CONCLUSIONES}

Pese a que se considera que la infección por LB tiene una incidencia baja a nivel mundial y con su mayor reporte a nivel de regiones asiáticas, se considera que en nuestro medio se debe considerar como diagnóstico diferencial en paciente cuya sintomatología no presenta mejoría clínica ni radiológica con antibioticoterapia convencional, especialmente si se trata de pacientes con alguna inmunodeficiencia reportada aunque también en pacientes inmunocompetentes que presenten profesiones que involucren posible exposición a animales o vectores que contribuyen a la infección parasitaria

En países como el Ecuador hay la probabilidad de que se infradiagnostiquen infecciones pulmonares secundarias a parásitos debido a la falta de acceso a estudios especializados en regiones rurales y considerando adicionalmente el uso indiscriminado de antiparasitarios por parte de las comunidades que podría estar enmascarando una infección pulmonar parasitaria que aún no debutan de manera considerable para ser tratadas como tal. 


\section{Referencias}

1.- González N, Otero F, et al, Bronchopulmonary infection by Lophomonas blattarum in a pediatric patient after hematopoietic progenitor cell transplantation: first report in Mexic, $\mathbf{J}$ Thorac Dis 2017;9(10): E899-E902

2.- Yao G, Zhou B, Zeng L. Imaging characteristics of bronchopulmonary Lophomonas blattarum infection: case report and literature review. J Thorac Imaging. 2009 Feb;24(1):49-51.

3.- Thakur c, Verma s, et.al lophomona blattarum coinfection in a patient with multidrugresistant tuberculosis. Int j tuberc lung dis. 2017 oct 1;21(10):1185-1187

4.- Li R, Gao ZC. Bronchopulmonary lophomonas blattarum Infection: Still a Pending Issue. Chin Med J (Engl). 2017 Jan 5;130(1):118.

5.- Van Woerden HC, Martinez R. Lophomonas blattarum: Is it Only its Morphology that Prevents its Recognition?, Chin Med J (Engl). 2017 Jan 5;130(1):117.

6.- Martínez r, Martínez c. The prevalence of protozoa in the gut of german cockroaches (blattella germanica) with special reference to lophomonas blattarum. Parasitol res. 2017 nov;116(11):3205-3210.

7.- Tyagi R, Anand KB, Teple K, Negi RS. Lophomonas blattarum infection in immunocompetent patient. Lung India. 2016 Nov-Dec;33(6):667-668.

8.- Berenji F, Parian M, Fata A, Bakhshaee M, Fattahi F. First Case Report of Sinusitis with Lophomonas blattarum from Iran. Case Rep Infect Dis. 2016;2016:2614187.

9.- Li R, Gao ZC. Lophomonas blattarum Infection or Just the Movement of Ciliated Epithelial Cells? Chin Med J (Engl). 2016 Mar 20;129(6):739-42.

10.- Zerpa R, Oré E. Human respiratory tract infection due to Lophomonas spp. Rev Peru Med Exp Salud Publica. 2016 Oct-Dec;33(4):827-828

11.- Alam YH, Abdulaziz AM. Identification criteria of the rare multiflagellate Lophomonas blattarum: comparison of different staining techniques. Parasitol Res. 2015 Sep;114(9):3309-14. 
12.- Verma S, Verma G, Singh DV, Mokta J, Negi RS, Jhobta A, Kanga A. Dual infection with pulmonary tuberculosis and Lophomonas blattarum in India. Int J Tuberc Lung Dis. 2015 Mar;19(3):368-9.

13.- Xue J, Li YL, Yu XM, Li DK, Liu MF, Qiu JF, Xue JJ. Bronchopulmonary infection of lophomonas blattarum: a case and literature review.Korean J Parasitol. 2014 Oct;52(5):521-5.

14.- Martínez- R, Van Woerden HC. The burden of Lophomonas blattarum under the light microscope. J Thorac Dis. 2014 Sep;6(9): E191-2.

15.- Zeng H, Kong X, Chen X, Luo H, Chen P, Chen Y. Lophomonas blattarum infection presented as acute exacerbation of chronic obstructive pulmonary disease.J Thorac Dis. 2014 Jun;6(6):E73-6.

16.-Martinez R, Van Woerden H, Lophomonas blattarum and bronchopulmonary Disease, Journal of Medical Microbiology, 2013, 62, 1641-1648.

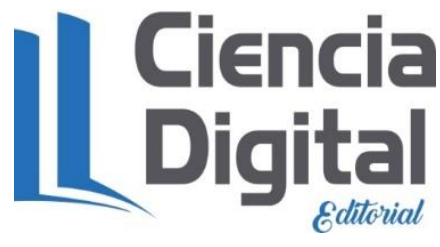




\section{PARA CITAR EL ARTÍCULO INDEXADO.}

Valdiviezo Allauca, N., Chávez Berrones, M., Merino Guerrero, C., \& Ayala Vaca, J. (2019). Infección broncopulmonar por lophomona blattarum en paciente inmunocompetente: primer $\begin{array}{llll}\text { reporte en } & \text { Ecuador. Ciencia } & \text { 309-318. }\end{array}$ https://doi.org/10.33262/cienciadigital.v3i3.3.823

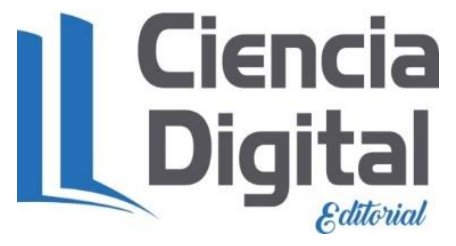

El artículo que se publica es de exclusiva responsabilidad de los autores y no necesariamente reflejan el pensamiento de la Revista Ciencia Digital.

El artículo queda en propiedad de la revista y, por tanto, su publicación parcial y/o total en otro medio tiene que ser autorizado por el director de la Revista Ciencia Digital.
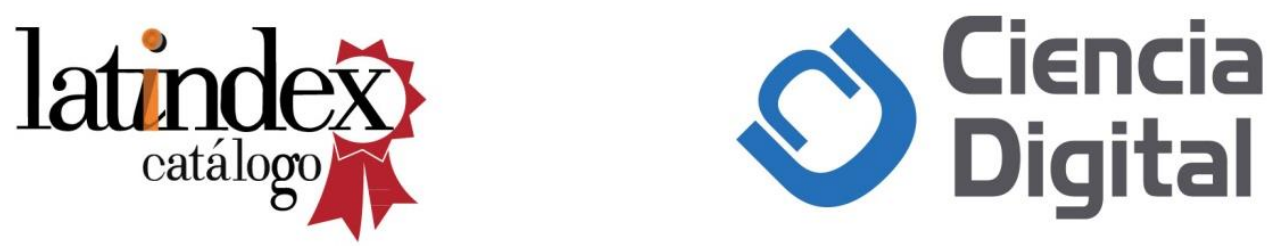